Глава 8.

\title{
ЛАНДШАФТНОЕ СТРОИТЕЛЬСТВО
}

УДК: $581.524 .1+635.982+581.6$

doi: $10.31360 / 2225-3068-2019-70-230-238$

\section{БИОЛОГИЧЕСКИЕ ОСОБЕННОСТИ И ФИТОНЦИДНАЯ АКТИВНОСТЬ ДЕКОРАТИВНЫХ РАСТЕНИЙ В СОВМЕСТНЫХ КОМПОЗИЦИЯХ}

\author{
Цицилин А. Н., Фатеева Т. В. \\ Федеральное государственное бюджетное научное учреждение \\ «Всероссийский научно-исследовательский институт \\ лекарственных и ароматических растений», \\ 2. Москва, Россия, e-mail: fitovit@gmail.com
}

\begin{abstract}
Показано, что циперус очереднолистный является более конкурентноспособным видом по сравнению с традесканцией приречной, офиопогоном японским и циссусом ромболистным. Композиции, в которых циперус находится в меньшинстве по отношению к указанным видам (соотношение $1: 3$ ) имеют лучше развитую надземную часть, а также обладают высокой фитонцидной активностью. Эффект взаимодействия изученных видов, т. е. изменение продуктивности растений, обусловлен не аллелопатией, а другими факторами. Максимальная фитонцидная активность наблюдается в монопосадках циперуса очереднолистного 33-51 \%, у других видов их фитонцидная активность в монопосадках ниже. В совместных посадках наибольшая фитонцидная активность отмечается, когда циперус находится в большинстве или равных количествах с другими видами: с традесканцией приречной (36-38 \%), офиопогоном японским (26-39\%), циссусом ромболистным (30-33\%).
\end{abstract}

Ключевые слова: совместные посадки, циперус очереднолистный, традесканция приречная, офиопогон японский, циссус ромболистный, фитонцидная активность.

Растения в интерьерах довольно эффективно улучшают их воздушную среду путём выделения летучих фитоорганических веществ (ЛФОВ) $[5,8]$. Но часто, в связи с острым дефицитом подходящих мест для расположения комнатных растений, в большинстве помещений, необходимо использовать композиции разных видов растений (совместные посадки) в одном кашпо. Нередко, композиции нескольких растений имеют бо́льший декоративный эффект, чем монопосадки этих же видов. Существуют многочисленные работы по взаимному влиянию растений в открытом грунте $[1,9]$. Данных по совместному произрастанию растений в закрытых помещениях значительно меньше. Так, некоторые исследователи рекомендуют фитокомпозиции, состоящие 
из растений, требующих разного температурного и водного режима. Например, Толкачёва А. А. и Рабинович А. М. высаживают вместе пеперомию, бересклет жёлто-зелёный, можжевельник (без указания научных видовых названий) [6]. Другие исследователи сообщают о положительной совместимости кардамона с кипарисом, традесканции с алоэ и каланхоэ [4]. Однако авторы не приводят информации по особенностям роста и развития вместе растущих растений этих видов; отсутствуют данные о продолжительности времени в течение которого, указанные композиции сохраняют свои декоративные качества, а также нет других сведений, необходимых для практического использования указанных композиций в озеленении интерьеров.

Объекты и методы. В вегетационных опытах изучались особенности роста и фитонцидная активность моно- и совместных посадок, широко распространённых комнатных декоративных растений: циперуса очереднолистного (Cyperus alternifolius L.) с традесканцией приречной (Tradescantia fluminensis Vell.), офиопогоном японским (Ophiopogon japonicus (Thunb.) Ker Gawl) и циссусом ромболистным (Cissus alata Jacq.) $[5,8]$. Растения были взяты из биоколлекций лекарственных и ароматических растений тропической и субтропической флоры Ботанического сада ФГБНУ ВИЛАР. Опыты проводились в зимней теплице оранжерейно-тепличного комплекса Ботанического сада. Ежегодно в апреле - мае, в течение двух лет, вегетативно размноженные растения высаживались в пластиковые контейнеры емкостью 3 л, в 4-кратной повторности. Характеристика почвенно-торфяной смеси (рН солевая 6.1, азот 350 мг/кг, фосфор 410 мг/кг, калий 450 мг/кг). Влажность почвенно-торфяной смеси поддерживали на уровне 65-70 \% от полной влагоёмкости. Раз в месяц вносили подкормки комплексных минеральных удобрений (NPK 16:16:16) - 5 г/контейнер. Наблюдения за композициями проводились регулярно - 1 раз в 10-15 дней. В зависимости от вида растения измерялись высота/длина растения, число листьев/ побегов, количество и размер листьев и др. - в течение 9-12 месяцев. После окончания опытов срезалась вся надземная часть каждого экземпляра и взвешивалась. Выкапывалась подземная часть каждого растения, которая отмывалась от почвы и после суточного просушивания взвешивалась.

Схемы опытов:

Посадки циперуса очереднолистного и традесканции приречной.

- циперус - 4 растения в контейнере (Ц4);

- традесканция - 4 растения в контейнере (Т4);

- 3 растения циперуса + 1 растение традесканции в контейнере (Ц3 + Т);

-2 растения циперуса +2 растения традесканции в контейнере (Ц2 + Т2); 
-1 растение циперуса + 3 растения традесканции в контейнере (Ц + Т3). Посадки циперуса очереднолистного и циссуса ромболистного.

- циперус - 4 растения в контейнере (Ц4);

- циссус - 4 растения в контейнере (Цс4);

-3 растения циперуса +1 растение циссуса в контейнере (Ц3 + Цс );

-2 растения циперуса +2 растения циссуса в контейнере (Ц $2+$ Цс2);

-1 растение циперуса +3 растения циссуса в контейнере $(Ц+$ Цс3).

Посадки циперуса очереднолистного и офиопогона японского.

- циперус - 4 растения в контейнере (Ц4);

- офиопогон - 4 растения в контейнере $(\mathrm{O} 4)$;

-3 растения циперуса +1 растение офиопогона в контейнере $(Ц 3+0)$;

-2 растения циперуса +2 растения офиопогона в контейнере (Ц2 + O2);

1 растение циперуса +3 растения офиопогона в контейнере (Ц + O3).

Для определения фитонцидной активности растения в контейнере помещали в боксы из оргстекла размером $0,5 \times 0,5 \times 0,7$ м. В верхней части бокса на сетке помещали перевёрнутые кверху дном чашки Петри с твёрдой питательной средой (МПА) с заражёнными из воздушной среды микроорганизмами. В контрольный бокс такого же размера помещали точно такой же контейнер с почвой, но без растения. Сверху боксы закрывали листом оргстекла. Заражение стерильных чашек Петри микроорганизмами воздушной среды проводили общепринятым седиментационным методом. Чашки Петри с застывшей питательной средой оставляли в помещении открытыми на 30 мин, затем их закрывали и ставили 4 чашки для контроля заражения в термостат при температуре $+36{ }^{\circ} \mathrm{C}$, оставшиеся чашки помещали кверху дном на выдвигающуюся решётку, расположенную наверху бокса. Чашки Петри вынимали из опытного и контрольного боксов через 1 час, 2 часа, 4, 6 и 24 часа после постановки растений и ставили в термостат при температуре $+36{ }^{\circ} \mathrm{C}$. Через 24 часа инкубации в термостате каждой из чашек их вынимали и проводили подсчёт колоний.

Оценку фитонцидной активности растений (ФА) рассчитывали по формуле:

$$
\Phi A=\frac{\hat{E}-\hat{I}}{\hat{E}} \times 100 \%
$$

где:

К - число микроорганизмов в контроле;

О - число микроорганизмов в опыте.

Результаты взаимодействия растений обрабатывали по методике Ван Ден Берга и Энника. Формы взаимодействия отличаются различными величинами RYT (relative yield total). 


$$
\mathrm{RYT}=\mathrm{T}_{\mathrm{a}}+\mathrm{T}_{\mathrm{b}}=\mathrm{O}_{\mathrm{a}} / \mathrm{M}_{\mathrm{a}}+\mathrm{O}_{\mathrm{b}} / \mathrm{M}_{\mathrm{b}}
$$

где:

a и b - взаимодействующие виды растений;

$\mathrm{O}$ - урожай (биомасса) на единицу площади в смешанной посадке;

М - урожай (биомасса) того же вида в одновидовой посадке при одинаковых условиях (за исключением межвидовой конкуренции).

Считается, что при значении RYT $<1$ - снижение продуктивности растений можно объяснить аллелопатией. Если RYT $>1$, то эффект взаимодействия обусловлен другими факторами $[2,10]$. Статистическую обработку данных проводили по Б. А. Доспехову [3].

Результаты и их обсуждение. Фитонцидные свойства и декоративные качества растений в большой степени зависят от фитомассы растения, особенно надземной. Чем сильнее у растения развита листовая поверхность, тем более оно активно в отношении микрофлоры воздуха. К тому же хорошо облиственное растение и выглядит более декоративно.

В опытах с циперусом очереднолистным и традесканцией приречной у циперуса во всех вариантах наблюдается превышение массы подземной части по отношению к надземной. У традесканции ситуация совершенно противоположная - надземная часть имеет намного большую биомассу по сравнению с подземной во всех вариантах (табл. 1). Полученные результаты указывают, что в изученных вариантах совместной посадки наблюдается стимулирование роста надземной и подземной биомассы циперуса только тогда, когда он находится в меньшинстве по отношению к традесканции. В этом случае существует достоверное увеличение надземной массы в 3,4 раза и подземной части циперуса на 121,1 \% по сравнению с его монопосадкой. Циперус в этом варианте образует, в среднем 7,75 стеблей, что больше в 3,2 раза, чем, когда он растет один и в 2,1-3,1 раз, когда циперус находится в большинстве или в равном количестве с традесканцией.

У традесканции под влиянием циперуса наблюдается достоверное снижение надземной части во всех вариантах. Масса подземной части в совместных посадках также снижается, когда традесканция находится в меньшинстве или равна по количеству растениям циперуса (варианты Ц3 + Т и Ц2 + Т2). Результаты опытов показывают, что циперус очереднолистный является более сильным компонентом в совместных посадках с традесканцией приречной в варианте при соотношении количества растений циперуса и традесканции $1: 3$ (табл. 1). 
Накопление биомассы

Таблица 1

\section{растениями циперуса очереднолистного и традесканции приречной в моно- и совместных посадках, в среднем на одном растении}

\begin{tabular}{|c|c|c|c|c|c|}
\hline \multirow{2}{*}{$\begin{array}{c}\text { № } \\
\text { пп }\end{array}$} & Варианты & $\begin{array}{c}\text { Циперус очереднолистный } \\
\text { Масса } \\
\text { надземной } \\
\text { части, 2 }\end{array}$ & $\begin{array}{c}\text { Масса } \\
\text { подземной } \\
\text { части, 2 }\end{array}$ & $\begin{array}{c}\text { Традесканция приречная } \\
\text { надземной } \\
\text { части, 2 }\end{array}$ & $\begin{array}{c}\text { Масса } \\
\text { подземной } \\
\text { части, 2 }\end{array}$ \\
\hline 1 & Ц4 & 23,6 & 60,3 & - & - \\
\hline 2 & Т4 & - & - & 24,0 & 0,47 \\
\hline 3 & Ц3+Т & 21,5 & 50,2 & 9,4 & 0,12 \\
\hline 4 & Ц2+Т2 & 30,5 & 57,1 & 8,0 & 0,24 \\
\hline 5 & Ц+Т3 & 80,9 & 133,3 & 11,4 & 0,44 \\
\hline 6 & НСР & 5,9 & 8,2 & 4,8 & 0,03 \\
\hline
\end{tabular}

В эксперименте с циперусом очереднолистным и офиопогоном японским у обоих видов во всех вариантах наблюдается превышение массы подземной части по отношению к надземной. Как и в опытах циперуса с традесканцией наблюдается стимулирование роста надземной и подземной биомассы циперуса только, когда он находится в меньшинстве по отношению к другой культуре, в данном случае к офиопогону. В этом случае наблюдается достоверное увеличение надземной массы на 44,8 \% и подземной части циперуса на 107,3 \% по сравнению с его монопосадкой. У офиопогона под влиянием циперуса наблюдается только достоверное увеличение подземной части во всех вариантах, масса же надземной части в совместных посадках снижается. Результаты опыта показывают, что циперус очереднолистный является более сильным компонентом в совместных посадках с офиопогоном японским в варианте при соотношении количества растений циперуса и офиопогона $1: 3$ (табл. 2).

В опытах с циперусом очереднолистным и циссусом ромболистным у циперуса во всех вариантах наблюдается превышение массы подземной части по отношению к надземной. У циссуса ромболистного надземная часть имеет большую биомассу по сравнению с подземной во всех вариантах совместных посадок (табл. 3). В изученных вариантах совместных посадок наблюдается стимулирование роста надземной и подземной биомассы циперуса только, когда он находится в меньшинстве по отношению к циссусу. В этом случае наблюдается достоверное увеличение надземной массы на 133,8 \% и подземной части циперуса 
Глава 8. Ландшафтное строительство

на 129,9 \% по сравнению с его монопосадкой. У циссуса под влиянием циперуса наблюдается снижение надземной и подземной части во всех вариантах совместных посадках. Результаты опыта показывают, что циперус очереднолистный является более сильным компонентом в совместных посадках с офиопогоном японским (табл. 3).

\section{Накопление биомассы}

Таблиияа 2

\section{растениями циперуса очереднолистного и офиопогона японского}

в моно- и совместных посадках, в среднем на 1 растение

\begin{tabular}{|c|c|c|c|c|c|}
\hline \multirow[b]{2}{*}{$\begin{array}{l}\text { № } \\
\text { ПП }\end{array}$} & \multirow[b]{2}{*}{ Варианты } & \multicolumn{2}{|c|}{ Циперус очереднолистный } & \multicolumn{2}{|c|}{ Офиопогон японский } \\
\hline & & $\begin{array}{c}\text { Масса } \\
\text { надземной } \\
\text { части, } 2\end{array}$ & $\begin{array}{c}\text { Масса } \\
\text { подземной } \\
\text { части, г }\end{array}$ & $\begin{array}{c}\text { Масса } \\
\text { надземной } \\
\text { части, } 2\end{array}$ & $\begin{array}{c}\text { Масса } \\
\text { подземной } \\
\text { части, г }\end{array}$ \\
\hline 1 & Ц4 & 42,2 & 59,9 & - & - \\
\hline 2 & $\mathrm{O} 4$ & - & - & 14,9 & 23,6 \\
\hline 3 & Ц3 + O & 35,0 & 53,8 & 14,8 & 30,0 \\
\hline 4 & Ц2 + O2 & 40,3 & 54,9 & 13,8 & 30,3 \\
\hline 5 & Ц + O3 & 61,1 & 82,7 & 12,7 & 27,4 \\
\hline 6 & $\mathrm{HCP}_{05}$ & 4,7 & 4,1 & 0,9 & 2,9 \\
\hline
\end{tabular}

Таблица 3

\section{Накопление биомассы}

растениями циперуса очереднолистного и циссуса ромболистного в моно- и совместных посадках, в среднем на 1 растение

\begin{tabular}{|c|c|c|c|c|c|}
\hline \multirow[b]{2}{*}{$\begin{array}{l}\text { № } \\
\text { ПП }\end{array}$} & \multirow[b]{2}{*}{ Варианты } & \multicolumn{2}{|c|}{ Циперус очереднолистный } & \multicolumn{2}{|c|}{ Циссус ромболистный } \\
\hline & & $\begin{array}{c}\text { Масса } \\
\text { надземной } \\
\text { части, г }\end{array}$ & $\begin{array}{c}\text { Масса } \\
\text { подземной } \\
\text { части, г }\end{array}$ & $\begin{array}{c}\text { Масса } \\
\text { надземной } \\
\text { части, 2 }\end{array}$ & $\begin{array}{c}\text { Масса } \\
\text { подземной } \\
\text { части, г }\end{array}$ \\
\hline 1 & Ц4 & 36,4 & 72,8 & - & - \\
\hline 2 & Цс4 & - & - & 9,7 & 9,3 \\
\hline 3 & Ц3 + Цс & 36,1 & 77,5 & 4,1 & 2,5 \\
\hline 4 & Ц2 +Цс2 & 59,9 & 97,2 & 4,8 & 2,1 \\
\hline 5 & Ц +Цc3 & 85,1 & 167,4 & 4,9 & 2,9 \\
\hline 6 & $\mathrm{HCP}_{0,5}$ & 14,2 & 28,6 & 1,2 & 0,5 \\
\hline
\end{tabular}

Аналогичные результаты были получены нами при изучении циперуса очереднолистного и хлорофитума хохлатого (Chlorophytum comosum (Thunb.) Jacques) в совместных посадках. У циперуса очереднолистного за время проведения эксперимента во всех вариантах наблюдается превышение массы подземной части по отношению к 
надземной. Также отмечено стимулирование роста надземной и подземной биомассы циперуса, когда он находил в меньшинстве по отношению к хлорофитуму. В этом случае происходило достоверное увеличение надземной массы в 1,8 раза и подземной части циперуса почти на $71 \%$ по сравнению с его монопосадкой [7].

В результате исследований выяснено, что наибольшие величины взаимодействия растений наблюдаются, когда циперус находится в меньшинстве по сравнению с другими видами (традесканцией приречной, офиопогоном японским и циссусом ромболистным) в контейнере-RYT = 2,7-3,03; при равном соотношении растений изучаемых видов RYT снижается до $1,38-2,19$; при увеличении количества растений циперуса по сравнению с другими видами RYT минимальный и равен 1,15-1,99. Таким образом, RYT всегда больше 1, поэтому согласно Ван Ден Берг и Энник эффект взаимодействия изученных видов, т. е. изменение продуктивности растений, обусловлен не аллелопатией, а другими факторами.

Во всех опытах максимальная фитонцидная активность наблюдается в монопосадках циперуса очереднолистного 33-51 \%, у других видов их фитонцидная активность в монопосадках ниже. Так, у офиопогона японского фитонцидная активность $14 \%$, циссуса ромболистного - $24 \%$, традесканции приречной - 27 \%. В совместных посадках наибольшая фитонцидная активность отмечается, когда циперус находится в большинстве или равных количествах с другими видами: с традесканцией приречной (36-38 \%), с офиопогоном японским (26-39 \%), с циссусом ромболистным (30-33 \%).

Заключение. Результаты проведённых опытов свидетельствуют о том, что циперус очереднолистный является более конкурентноспособным видом по сравнению с традесканцией приречной, офиопогоном японским и циссусом ромболистным. Композиции, в которых циперус находится в меньшинстве по отношению к указанным видам (соотношение $1: 3$ ) имеют высокие декоративные качества, выражающиеся в лучшем развитии надземной части, в течение длительного периода времени (10-12 месяцев и более), а также они обладают высокой фитонцидной активностью. Таким образом, путём подбора оптимальных соотношений количества высаженных особей в совместных посадках, можно повысить декоративные свойства и фитонцидную активность композиций в течение долгого времени, что очень важно для эффективного использования растений при оздоровлении воздушной среды помещений.

Работа выполнена согласно теме №0576-2019-0008 «Научное формирование, сохранение и изучение биоколлекций различного направления с целью создания новых лекарственных средств и оздоровления среды обитания человека» 


\title{
Библиографический список
}

1. Гродзинский А.М. Аллелопатия растений и почвоутомление. - Киев: Наукова думка, 1991. - 432 с. - ISBN 5-12-001928-5.

2. Ван Ден Берг Я.П., Энник Г.С. Взаимоотношение между видами растений // Физиологобиохимические основы взаимодействия растений в фитоценозах (сборник научных трудов): [ред.кол. А. М. Гродзинский и др.]. - Киев: Наукова думка, 1973. - Вып. 4. - С. 47-57. 3. Доспехов Б.А. Методика полевого опыта. - М.: Колос, 1985. - 335 с.

4. Жученко А.А.-мл., Труханов А.И. Средоулучшающие фитотехнологии в северных мегаполисах. - М.: Красанд, 2009. - 192 с. - ISBN 978-5-396-00114-5.

5. Казаринова Н.В., Ткаченко К.Г. Здоровье дарят комнатные растения. - СПб.: Нева, 2003. - 128 c. - ISBN 5-7654-2379-5.

6. Толкачёва А.А., Рабинович А.М. Создание устойчивых фитокомпозиций фитонцидных и декоративных растений в интерьерах помещений различного назначения // Новые и нетрадиционные растения и перспективы их использования: материалы VI Междунар. симп., Москва, Пущино 13-17 июня 2005 г. - М., 2005. - T. III. - C. 453-454. - ISBN 5-209-04178-6.

7. Цицилин А.Н., Фатеева Т.В., Шипулина Л.Д. Биологические особенности и фитонцидная активность хлорофитума хохлатого и циперуса очереднолистного в совместных композициях // Вопросы биологической, медицинской и фармацевтической химии, 2012. - № 7. - С. 18-20. - ISBN 1560-9596.

8. Цицилин А.Н. Фитодизайн: как вырастить здоровый воздух в офисе и дома. - М.: Эксмо, 2011. - 272 с. - ISBN 978-5-699-42220-3.

9. Allelopathy in Sustainable Agriculture and Forestry / Editors Ren Sen Zeng, Azim U. Mallik // Shiming Luo. - New York, Springer-Verlag, 2008. - 412 P. - ISBN 978-0-38777336-0

10. Bergh J.P. van den: Competition based on mono-and bicultures // Acta Bot. Neerl, 1973. - Vol. 22. - P. 259-260. - ISBN 0044-5983.

\section{BIOLOGICAL FEATURES AND PHYTONCIDAL ACTIVITY OF ORNAMENTAL PLANTS IN JOINT COMPOSITIONS}

\author{
Tsitsilin A. N., Fateeva T. V. \\ Federal State Budgetary Scientific Institution \\ "Russian Research Institute of Medicinal and Aromatic Plants", \\ c. Moscow, Russia, e-mail: fitovit@gmail.com
}

It is shown that umbrella papyrus (Cyperus alternifolius L.) is a more competitive species compared to small-leaf spiderwort (Tradescantia fluminensis Vell.), dwarf lilyturf (Ophiopogon japonicus (Thunb.), vleilelie (Ker Gawl) and Buddha coconut (Cissus alata Jacq.) Compositions in which umbrella papyrus is in the minority in relation to the indicated species $(1: 3$ ratio) have a better developed above ground part, and also have high phytoncidal activity. The effect of the interaction of the studied species, i.e. the change in plant productivity is not due to allolopathy. The maximum phytoncidal activity is observed in monoplantings of umbrella papyrus $33-51 \%$, in other species their phytoncidal activity in monoplantings is 
lower. In joint plantings, the greatest phytoncidal activity is observed when umbrella papyrus is in most or equal quantities with other species: with small-leaf spiderwort (Tradescantia fluminensis) (36-38 \%), dwarf lilyturf (Ophiopogon japonicas) (26-39\%), Buddha coconut (Cissus alata) (30-33\%).

Key words: joint plantings, umbrella papyrus, small-leaf spiderwort, dwarf lilyturf, vleilelie, Buddha coconut phytoncidal activity. 